\title{
Left ventricular unloading using a percutaneous paracorporeal left ventricular assist device - University Hospital Centre Zagreb experience
}

\author{
DDubravka Šipuš ${ }^{*}$ \\ (-) Ivo Planinc, \\ BBoško Skorić, \\ - Vedran Velagić, \\ DDaniel Lovrić, \\ (D) Hrvoje Jurin, \\ CMarijan Pašalić, \\ (1) Jure Samardžić, \\ (1) Jana Ljubas Maček, \\ (-)Hrvoje Gašparović, \\ -Bojan Biočina, \\ -Davor Miličić, \\ CMaja Čikeš
}

University of Zagreb School of Medicine, University Hospital Centre Zagreb, Zagreb, Croatia

RECEIVED:

December 14, 2020

ACCEPTED:

December 18, 2020

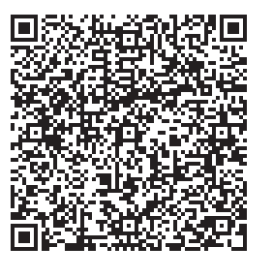

KEYWORDS: cardiogenic shock, extracorporeal membrane oxygenation, ProtekSolo, left ventricular unloading.

CITATION: Cardiol Croat. 2021;16(1-2):31-2. | https://doi.org/10.15836/ccar2021.31

*ADDRESS FOR CORRESPONDENCE: Dubravka Šipuš, Klinički bolnički centar Zagreb, Kišpatićeva 12, HR-10000 Zagreb, Croatia. / Phone: +385-91-7344878 / E-mail: dubravka.sipus@gmail.com

ORCID: Dubravka Šipuš, https://orcid.org/0000-0002-5631-0353 • Ivo Planinc, https://orcid.org/0000-0003-0561-6704 Boško Skorić, https://orcid.org/0000-0001-5979-2346 • Vedran Velagić, https://orcid.org/0000-0001-5425-5840 Marijan Pašalić, https://orcid.org/0000-0002-3197-2190 • Hrvoje Jurin, https://orcid.org/0000-0002-2599-553X Daniel Lovrić, https://orcid.org/0000-0002-5052-6559 • Jure Samardžić, https://orcid.org/0000-0002-9346-6402 Jana Ljubas Maček, https://orcid.org/0000-0001-7171-2206 • Hrvoje Gašparović, https://orcid.org/0000-0002-2492-3702 Bojan Biočina, https://orcid.org/0000-0003-3362-9596 • Davor Miličić, https://orcid.org/0000-0001-9101-1570 Maja Čikeš, https://orcid.org/0000-0002-4772-5549

|IIIIIIIIIIIIIIIIIIIIIIIIIIIIIIIIIIIIIIIIIIIIIIIIIIIIIIIIIIIIIIIIIIIIIIIIIIIIIIIIIIIIIIIIIIIIIIIIIIIIIIIIIIIIIIIIIII Background: Veno-arterial extracorporeal membrane oxygenation (VA-ECMO) is widely used in refractory cardiogenic shock and cardiac arrest but is characterized by increased left ventricular (LV) afterload and consequent development of pulmonary oedema (ECMO lungs). The ProtekSoloTM (LivaNova, IT) cannula is inserted via the right femoral vein to the left atrium, by a trans-septal puncture (under the guidance of transesophageal echocardiography and fluoroscopy). This bypasses the LV by draining blood from the left atrium to a paracorporeal pump (eg Rotaflow pump (Maquet, DE)) and returning it via a femoral artery cannula, thus providing direct unloading of $\mathrm{LV}^{1-3}$ We aimed to demonstrate our experience with the paracorporeal LV assist device using the ProtekSolo cannula and Rotaflow pump (PSp-LVAD).

Patients and Methods: 7 adult patients underwent PSp-LVAD placement in UHC Zagreb from January to December 2020. We divided the patients in two groups: those who required PSp-LVAD to treat ECMO

TABLE 1. Baseline characteristics.

\begin{tabular}{llll}
\hline N & 7 & N & 7 \\
\hline Mean age (years) & $56 \pm 9.3$ & Heart rate (beats/min) & $90(85-125)$ \\
\hline Sex (male \%) & $7(100 \%)$ & Urinary output hourly (ml/h) & $100(15-180)$ \\
\hline Mean BMI (kg/m²) & $25.5 \pm 2.9$ & Laboratory values \\
\hline Aetiology of cardiogenic shock & & Lactate (mmol/L) & $2.1(0.4-4.8)$ \\
\hline \multicolumn{1}{c}{ Worsening of chronic heart failure } & $4(57.1 \%)$ & BUN (mmol/L) & $11.5(1.9-19.7)$ \\
\hline \multicolumn{1}{c}{ Acute coronary syndrome } & $3(42.9 \%)$ & Creatinine (umol/L) & $91(61-133)$ \\
\hline Duration of disease & & AST (IU/L) & $193(19-2132)$ \\
\hline \multicolumn{1}{c}{ Cardiomyopathy (years) } & $8 \pm 5.3$ & ALT (IU/L) & $75(17-566)$ \\
\hline \multicolumn{1}{c}{ Acute coronary syndrome (days) } & $5 \pm 6$ & NTproBNP (ng/L) & $8118(41-26245)$ \\
\hline SAVE score & $-3(-13,6)$ & Inotropic or vasopressor therapy & \\
& & before PSp-LVAD placement & \\
\hline VA-ECM0 prior to PSp-LVAD & $5(71.4 \%)$ & Dobutamine & $4(57.1 \%)$ \\
\hline ECMO lungs & $4(57.1 \%)$ & Milrinone & $3(42.9 \%)$ \\
\hline Infection prior to VA-ECMO & $4(57.1 \%)$ & Levosimendan & $4(57.1 \%)$ \\
\hline Mean arterial pressure (mmHg) & $76(60-79)$ & Norepinephrine & $5(71.4 \%)$ \\
\hline
\end{tabular}

BMI: body mass index, SAVE: Survival After Veno-arterial Ecmo, VA-ECMO: veno-arterial extra corporeal membrane oxygenation, PSp-LVAD: Protek Solo paracorporeal left ventricular assist device, BUN: blood urea nitrogen, AST: aspartate transaminase, ALT alanine transaminase, NTproBNP: N-terminal prohormone of brain natriuretic peptide. 
Left ventricular unloading using a percutaneous paracorporeal

left ventricular assist device - University Hospital Centre Zagreb experience

TABLE 2. Outcomes.

\begin{tabular}{lcc}
\hline & ECMO lungs before PSp-LVAD (N=4) & No ECMO lungs before PSp-LVAD (N=3) \\
\hline 30-day mortality & $3(75 \%)$ & $1(33 \%)$ \\
\hline Survival to decannulation & $1(25 \%)$ & $1(33 \%)$ \\
\hline Mean PSp-LVAD days & $11 \pm 5$ & $32.5 \pm 12$ \\
\hline VA-ECMO prior to PSp-LVAD & $4(100 \%)$ & $1(33 \%)$ \\
\hline Removal of oxygenator & $2(50 \%)$ & $3(100 \%)$ \\
\hline Durable LVAD implantation & $0(0 \%)$ & $1(33 \%)$ \\
\hline Complications & & $1(33 \%)$ \\
\hline \multicolumn{1}{c}{ Infective } & $4(100 \%)$ & $1(33 \%)$ \\
\hline \multicolumn{1}{c}{ Bleeding } & $2(50 \%)$ & \\
\hline
\end{tabular}

VA-ECMO: veno-arterial extra corporeal membrane oxygenation, PSp-LVAD: Protek Solo paracorporeal left ventricular assist device, LVAD: left ventricular assist device.

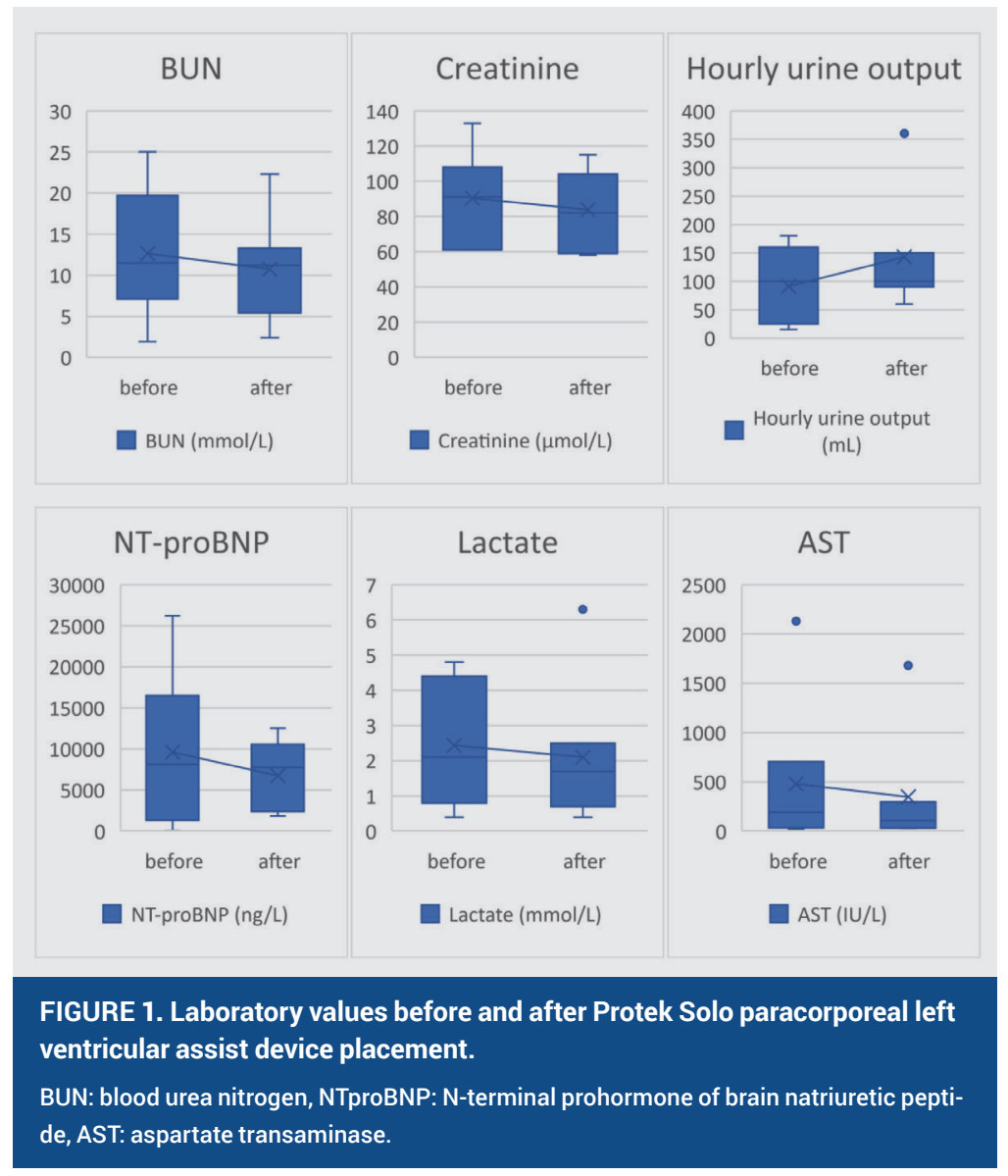

lungs $(n=4)$ and those who received PSp-LVAD implantation prior to developing ECMO lungs $(n=3)$. In addition to the description of the treated patients, we also assessed 30-day all-cause mortality.

Results: The baseline characteristics of patients are shown in Table 1. All patients were male, mean age $56 \pm 9.3$ years. $57.1 \%$ of patients underwent PSp-LVAD placement due to worsening of chronic heart failure and $42.9 \%$ due to acute coronary syndrome. Concurrent infection was present in $57.1 \%$ of patients. $71.4 \%$ were first on VA-ECMO support, of those $80 \%$ developed ECMO lungs. Laboratory tests (Figure 1) show improvement in kidney and liver function after PSp-LVAD placement. Outcomes are shown in Table 2; patients in prophylactic group have lower observed 30-day mortality rate (33\% vs $75 \%$ ) and longer VA-ECMO support duration due to lower mortality. Besides 2 patients who are still in active treatment, all others died during initial hospitalization due to infective complications, predominantly those that had a concurrent infection upon institution of the PSp-LVAD.

Conclusion: Pulmonary edema (ECMO lungs) due to increased LV afterload is a major complication of VA-ECMO. Prophylactic LV unloading by PSp-LVAD seems associated with lower 30-days mortality.

LITERATURE IIIIIIIIIIIIIIIIIIIIIIIIIIIIIIIIIIIIIIIIIIIIIIIIIIIIIIIIIIIIIIIIIIIIIIIIIIIIIIIIIIIIIIIIIIIIIIIIIIIIIIIIIIIIIIIIIIIIIIIIIIIIIIIIIIIIIIIII

1. Russo JJ, Aleksova N, Pitcher I, Couture E, Parlow S, Faraz M, et al. Left Ventricular Unloading During Extracorporeal Membrane Oxygenation in Patients With Cardiogenic Shock. J Am Coll Cardiol. 2019 Feb 19;73(6):654-662. https://doi.org/10.1016/j.jacc.2018.10.085

2. Meani P, Gelsomino S, Natour E, Johnson DM, Rocca HB, Pappalardo F, et al. Modalities and Effects of Left Ventricle Unloading on Extracorporeal Life support: a Review of the Current Literature. Eur J Heart Fail. 2017 May;19 Suppl 2:84-91. https://doi.org/10.1002/ejhf.850

3. Na SJ, Yang JH, Yang JH, Sung K, Choi J0, Hahn JY, Jeon ES, Cho YH. Left heart decompression at venoarterial extracorporeal membrane oxygenation initiation in cardiogenic shock: prophylactic versus therapeutic strategy. J Thorac Dis. 2019 Sep;11(9):3746-3756. https://doi.org/10.21037/jtd.2019.09.35 